\title{
Effect of B-Lynch Suture: Bleeding Control and Asherman's Syndrome
}

\author{
Kemine Uzel ${ }^{1}$, Igor V Lakhno ${ }^{2}$
}

\begin{abstract}
Aim and objective: The study was aimed to investigate possible complications such as intrauterine synechiae following the B-Lynch suture, which was used to control postpartum hemorrhage (PPH).

Materials and methods: Our study included 36 patients, which underwent B-Lynch suture due to PPH from 2013 to 2015.

Results: Asherman's syndrome was found in $3(8.3 \%)$ of 36 patients who participated in the study. Two patients with Asherman's syndrome had a history of placenta accreta and one patient placenta previa.

Conclusion: Compared to procedures that require experiences such as hysterectomy or internal iliac artery ligation, B-Lynch suture is a highlevel PPH approach that preserves fertility potential with preventing complications.

Keywords: Asherman's syndrome, B-Lynch, Fertility, Hysteroscopy.

Journal of South Asian Federation of Obstetrics and Gynaecology (2021): 10.5005/jp-journals-10006-1854
\end{abstract}

\section{INTRODUCTION}

Postpartum hemorrhage (PPH), which causes significant maternal losses worldwide, is an important obstetric emergency., ${ }^{1,2}$

PPH caused by insufficiency of myotamponade or thrombotamponade is blood loss of more than $500 \mathrm{~mL}$ vaginally or more than $1,000 \mathrm{~mL}$ on the first day after cesarean delivery. This is an obstetric emergency that requires a clinical experience. ${ }^{1,2}$ The most important reason is uterine atony. ${ }^{3}$ B-Lynch ${ }^{4}$ compression suture, which reduces the rate of hysterectomy and preserves fertility, is a method that surgeons can use safely in control of PPH.

Since 1997, the B-Lynch suture surgical technique has been successfully used for the surgical treatment of PPH is uterine atony where the medical treatment of postpartum hemorrhages has failed. The trial of this method, which protects menstrual function and pregnancies, does not require much experience ${ }^{5} \mathrm{It}$ is a method that has few complications, is easy to apply, reduces the rate of hysterectomy, and also gives confidence. ${ }^{6}$

From the uterus wall are vertical sutures that pass through the anterior-posterior, and this technique is a compressive suture. ${ }^{7}$ Different suture placement sites are suggested, different modifications of the originally described technique (with open hysterectomy) have been proposed. ${ }^{8}$

The cause of amenorrhea after curettage, which was first described by Fritsch, is intrauterine adhesions (IUA). ${ }^{9}$ Asherman ${ }^{10}$ investigated 29 women with amenorrhea due to cavity trauma in 1950 and named this condition Asherman's syndrome (AS).

The pregnant uterus is sensitive to traumas and traumas in the basal layer can easily lead to intrauterine adhesions. Diagnostic and revision curettage, as well as procedures that destroy the basal layer, such as operative hysteroscopy, and uncontrolled scraping of the cavity after myomectomy and cesarean delivery, genital tuberculosis are factors that need to be investigated among the causes. ${ }^{11-14}$ IUA, independent of glandular tissue, appears as a fibrous tissue with varying density. While investigating patients, encounter recurrent abortions, menstrual cycle disorders, pelvic pain, hematometra, and low pregnancy rates. ${ }^{15}$
${ }^{1}$ Department of Obstetrics and Gynecology, Erzincan Binali Yıldırım University Mengucek Gazi Training and Research Hospital, Erzincan, Turkey

${ }^{2}$ Department of Perinatology, Obstetrics and Gynecology, Kharkiv Medical Academy of Postgraduate Education, Kharkiv, Ukraine

Corresponding Author: Igor V Lakhno, Department of Perinatology, Obstetrics and Gynecology, Kharkiv Medical Academy of Postgraduate Education, Kharkiv, Ukraine, e-mail: igorlakhno71@gmail.com

How to cite this article: Uzel K, Lakhno IV. Effect of B-Lynch Suture: Bleeding Control and Asherman's Syndrome. J South Asian Feder Obst Gynae 2021;13(1):18-21.

Source of support: This study was not funded by any organization Conflict of interest: The authors declare to have no conflict of interest in this study

There are several methods for diagnosis IUA. Magnetic resonance imaging (MRI), ultrasonography (USG), and 3D (USG) are non-invasive methods, hysteroscopy, saline-infused sonohysterography (SIS), and hysterosalpingography (HSG) are invasive methods. Hysteroscopy is the gold standard in the diagnosis of cavity lesions and there are different classification systems based on these findings. HSG is very useful in evaluating filling defects and tubal patency. ${ }^{16,17}$ Significantly thinner endometrium has been reported in women with AS as a result of transvaginal ultrasonography (TVUSG) evaluations compared to women with normal menstruation. ${ }^{18}$

It was used a three-step classification of IUA based on the severity of extended adhesions found in hysteroscopy. ${ }^{11}$

\section{Materials and Methods}

\section{Study Design}

The ethical approval for scientific research No. 24.0918p has been taken from the Research Council and Ethical Committee of Kharkiv 


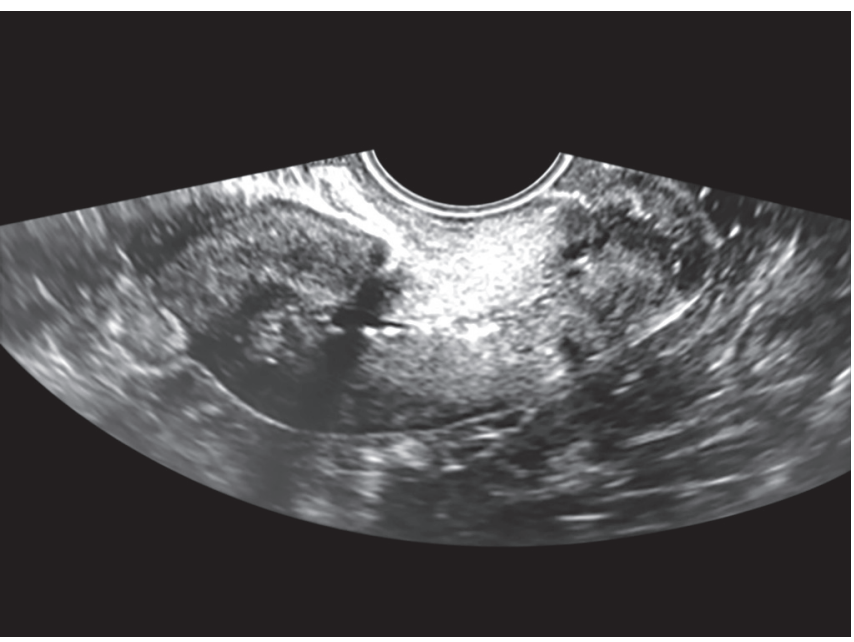

Fig. 1: Sagittal view by TVUSG showing thin endometrium and echogenic foci

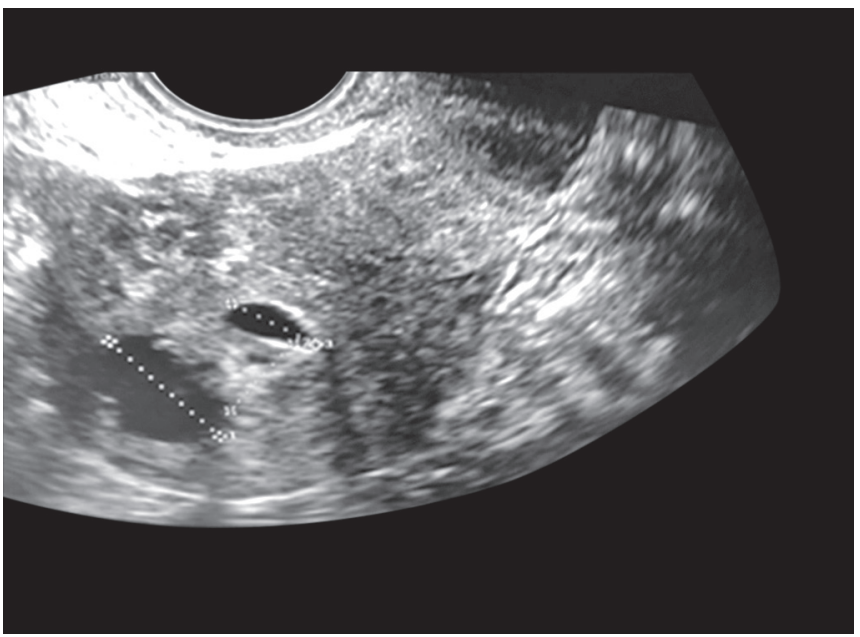

Fig. 2: SIS demonstrating intrauterine adhesion

Medical Academy of Postgraduate Education. Informed consent was obtained from the patient.

This research was done at the Obstetrics and Gynecology Department of Kharkiv Medical Academy of Postgraduate Education, Ukraine. Our study included 36 patients which underwent B-Lynch suture due to PPH. Patients' records were obtained and data collected.

For TVUSG evaluation, the midsagittal endometrial thickness was measured at the widest point in the middle of the menstrual period and at any time when the patients with amenorrhea came to the hospital (Fig. 1).

Pelvic ultrasonography was performed with Voluson P6 (GE Healthcare, USA).In view of this finding, saline-infused sonohysterography (SIS) (Fig. 2) was also performed.

All cases were diagnosed via hysteroscopy (Fig. 3). The severity and extent of IUAs were evaluated according to the American Fertility Association (AFS) (1988) classification system. ${ }^{19}$ Depending on the evaluations, a score of 1-4-mild, a score of 5-8-moderate, and a score of 9-12 were considered severe adhesions.

Hysteroscopy was performed at any time after the exclusion of pregnancy in women with amenorrhea, in the early proliferative

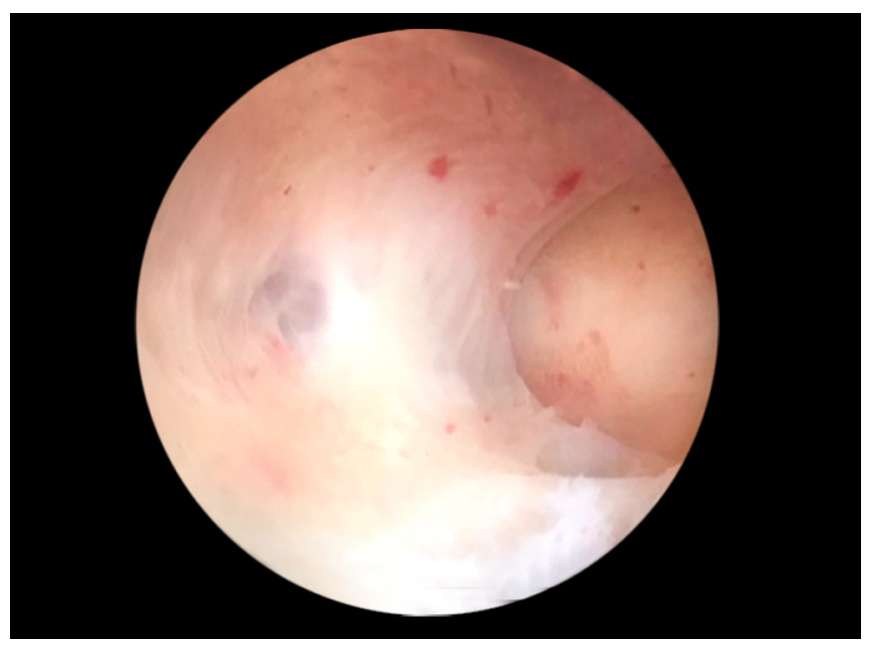

Fig. 3: View of endometrial adhesions with the hysteroscope

period in patients with regular menstruation. The patients were in the lithotomic position and the perineum and vagina were cleaned with antiseptics. The cervical channel was enlarged up to Hegar No. 7. The scissors were used for procedures. Uterine distention pressure was set to $70-100 \mathrm{~mm} \mathrm{Hg}$, and normal saline was used as the uterine distension medium. The surgeon completed the morphology examination after the IUA grade was evaluated as a result of the intracavitary evaluation. Microscissors were used to cut adhesions. Electric loop resection was not used for adhesions. Ultrasound was used in 11 patients to monitor the procedure. All patients were sent home in 2-3 h after surgery.

\section{Results}

The study included 36 women that underwent B-Lynch suture due to PPH.

The delivery method of all patients was cesarean. In $63.8 \%$ ( $n=23$ ) of the patients, the cause of cesarean was a previous cesarean, $11.1 \%(n=4)$ fetal distress, $5.5 \%(n=2)$ fetal macrosomia, $5.5 \%(n=2)$ placenta previa, 5.5\% $(n=2)$ intrauterine growth restriction (IUGR), $5.5 \%(n=2)$ anhydramnios, $2.7 \%(n=1)$ preterm placental abruption.

Median blood loss was 1,200 mL. Body mass index varied between 22.75 and $35.31 \mathrm{~kg} / \mathrm{m}^{2}$, an average of $29.77 \mathrm{~kg} / \mathrm{m}^{2}$ and $( \pm S D)\left( \pm 3.17 \mathrm{~kg} / \mathrm{m}^{2}\right)$, and parity between 0 and 4 .

The age of the patients was between 21 and 39 years, with a mean of 30.5 years and $( \pm S D)$ ( \pm 5 years).

Compression sutures were placed in $72.2 \%(n=26)$ of cases due to atony. The B-Lynch suture was placed during primary operation or reoperation. Postpartum hysterectomy was performed in one patient whose bleeding continued despite the B-Lynch suture, and internal iliac artery ligation was performed in two patients. Histological investigation revealed placenta increta in one patient and invasion anomaly or accreta in six patients (16.6\%).

A total of $83.3 \%(n=30)$ of patients' compression sutures were placed at the primary surgical intervention.

Asherman's syndrome developed in 3 of 36 (8.3\%) patients who participated in the study (Table 1). Two patients with Asherman's syndrome were diagnosed with placenta accreta and one with placenta previa. None of these patients had previous curettage history. 
Table 1: Patients with Asherman's syndrome characteristics

\begin{tabular}{|c|c|c|c|c|c|c|c|c|c|}
\hline $\begin{array}{l}\text { Patient } \\
\text { number }\end{array}$ & Age & Parity & $\begin{array}{l}\text { Patient past medical } \\
\text { history }\end{array}$ & $\begin{array}{l}\text { Endometrial } \\
\text { stripe }(\mathrm{mm})\end{array}$ & $B M I$ & $\begin{array}{l}\text { Dysmenorrheal } \\
\text { Amenorrheal } \\
\text { Hypomenorrheal } \\
\text { Dyspareunia }\end{array}$ & $F S H / L H / E 2$ & $A M H$ & $\begin{array}{l}\text { IUA } \\
\text { (AFS) } \\
\text { score }\end{array}$ \\
\hline & & & $\begin{array}{l}\text { History of C-section } \times 2 \\
\text { Postpartum hemorrhage }\end{array}$ & & & & & & \\
\hline 1 & 38 & G3P2 & Placenta previa & 4 & 32.2 & $+/-/+/-$ & $5.5 / 2.2 / 60.8$ & 1.49 & 5 \\
\hline 2 & 39 & G2P2 & $\begin{array}{l}\text { History of C-section } \times 2 \\
\text { Postpartum hemorrhage } \\
\text { Placenta accreta }\end{array}$ & 5 & 37.0 & $-1-/+1-$ & $36.6 / 28.4 / 61.4$ & 0.01 & 7 \\
\hline 3 & 32 & G1P1 & $\begin{array}{l}\text { History of C-section } \times 1 \\
\text { Postpartum hemorrhage } \\
\text { Placenta accreta }\end{array}$ & 5 & 22.7 & $-/-/+/+$ & 7.5/4.7/75.0 & 1.32 & 4 \\
\hline
\end{tabular}

\section{Discussion}

Since the increased risk of maternal mortality, postpartum hemorrhage is known to be an important obstetric emergency. The ligation of the hypogastric artery or the hysterectomy is the traditional surgical technique to get hemostasis. However, these procedures require a high level of surgical ability and education, both interventions are known to have possible complications. ${ }^{2}$

Different suture techniques have been defined for uterine compression. ${ }^{20-25}$ Different devascularization operations can be combined. Very few studies have informed long-term follow-up results after using compression sutures. ${ }^{20,23,25-30}$ About fertility, defined a few case series after B-Lynch sutures.

In a few studies, pregnancy was reported after this compression suture in only 13 patients. ${ }^{31-36}$ Observed AS after PPH due to placenta accreta has been reported. ${ }^{37}$ Also, the history of AS in $13 \%$ of cases with placenta accreta has been reported. ${ }^{38}$

In our study, AS developed in 3 of 36 (8.3\%) patients who participated in the study. Two patients with AS were diagnosed with a history of placenta accreta and one with placenta previa. Increasing numbers of recurrent cesarean sections around the world cause an elevation in abnormally invasive placental rates. In our study, the most important reason for placing B-Lynch sutures was uterine atony.

Endometritis and synechiae can cause adhesions by blocking the drainage of blood. At the same time, synechiae intrauterine infection can cause blood congestion in the uterine cavity. We believe it is the reason why we did not observe endometritis or synechiae with the B-Lynch suture, unlike the different compression sutures that do not interfere with lochia drainage.

As a result of our study, after PPH the main cause of the development of Asherman's syndrome is endometrial trauma which is caused by placental abnormalities. Safe conservative measure for the surgical treatment of $\mathrm{PPH}$ with protecting fertility, the outcome from this study recommends that B-Lynch compression suture is effective.

\section{Conclusion}

Compared to procedures that require experience with hysterectomy or internal iliac artery ligation, B-Lynch suture is a high-level PPH approach that preserves fertility potential with preventing complications.

\section{References}

1. Kainer F, Schiessl B, Kastner R. Geburtshilfliche Notfälle. Geburtsh Frauenheilkd Refresher 2003;28:161-184.

2. El-Rafaey H, Rodeck C. Post-partum haemorrhage: definitions, medical and surgical management. A time for change. Br Med Bull 2003;67:205-217. DOI: 10.1093/bmb/ldg016.

3. Khan KS, Wojclyle D, Say L, et al. WHO analysis of causes of maternal death: a systematic review. Lancet 2006;367(9516):1066-1074. DOI: 10.1016/S0140-6736(06)68397-9.

4. Romer Th, Mallmann P, Straube W. Pschyrembel Worterbuch Therapie in Gynakologie und Geburtshilfe. De Gruyter; 2001.

5. Tsitlakidis C, Alalade A, Danso D, et al. Ten year follow-up of effect of the B-Lynch uterine compression suture for massive postpartum hemorrhage. Int J Fertil Womens Med 2006;51(6):262-265.

6. Price N, B-Lynch C. Technical description of the B-Lynch brace suture for treatment of massive postpartum hemorrhage and review of published cases. Int J Fertil Womens Med 2005;50(4):148-163.

7. El-Hamamy E, Wright A, B-Lynch C. The B-Lynch suture technique for postpartum haemorrhage: a decade of experience and outcome. J Obstet Gynaecol 2009;29(4):278-283. DOI: 10.1080/01443610902797645.

8. Mallappa Saroja CS, Nankani A, El-Hamamy E. Uterine compression sutures, an update: review of efficacy, safety and complications of B-Lynch suture and other uterine compression techniques for postpartum haemorrhage. Arch Gynaecol Obstet 2010;281(4): 581-588. DOI: 10.1007/s00404-009-1249-z.

9. Fritsch $\mathrm{H}$. Ein fall von volligen Schwund Der Gebärmutterhohle nACh Auskratzung. Zentralbl Gynaekol 1894;18:1337-1342.10.

10. Asherman JG. Traumatic intra-uterine adhesions. J Obstet Gynaecol BrEmp 1950;57(6):892-896. DOI: 10.1111/j.1471-0528.1950.tb06053.x.

11. Valle RF, Sciarra JJ. Intrauterine adhesions: hysteroscopic diagnosis, classification, treatment, and reproductive outcome. Am J Obstet Gynecol 1988;158(6 Pt 1):1459-1470. DOI: 10.1016/ 0002-9378(88)90382-1.

12. Orhue $A A$, Aziken ME, Igbefoh JO. A comparison of two adjunctive treatments for intrauterine adhesions following Iysis. Int J Gynaecol Obstet 2003;82(1):49-56. DOI: 10.1016/ s0020-7292(03)00030-4.

13. Schenker JG. Etiology of and therapeutic approach to synechia uteri. Eur J Obstet Gynecol Reprod Biol 1996;65(1):109-113. DOI: 10.1016/0028-2243(95)02315-j.

14. Song $D$, Liu $Y$, Xiao $Y$, et al. A matched cohort study comparing the outcome of intrauterine adhesiolysis for Asherman's syndrome after uterine artery embolization or surgical trauma. J Minim Invasive Gynecol 2014;21(6):1022-1028. DOI: 10.1016/j.jmig.2014.04.015.

15. Berman JM. Intrauterine adhesions. Semin Reprod Med 2008;26(4):349-355. DOI: 10.1055/s-0028-1082393. 
16. Roma Dalfó $A$, Úbeda $B$, Úbeda $A$, et al. Diagnostic value of hysterosalpingography in the detection of intrauterine abnormalities: a comparison with hysteroscopy. AJR Am J Roentgenol 2004;183(5):1405-1409. DOI: 10.2214/ajr.183.5.1831405.

17. Soares SR, Barbosa dos Reis MM, Camargos AF. Diagnostic accuracy of sonohysterography, transvaginal sonography, and hysterosalpingography in patients with uterine cavity diseases. Fertil Steril 2000;73(2):406-411. DOI: 10.1016/s0015-0282(99)00532-4.

18. Lo St, Ramsay P, Pierson R, et al. Endometrial thickness measured by ultrasound in women with uterine outlet obstruction due to intrauterine or upper cervical adhesions. Human Reprod 2008;23(2):306-309. DOI: 10.1093/humrep/dem393.

19. March C, Israel R. Intrauterine adhesions secondary to elective abortion. Hysteroscopic diagnosis and management. Obstet Gynecol 1976;48(4):422-424.

20. Lynch C, Coker A, Lawal AH, et al. The B-Lynch surgical technique for the control of massive postpartum haemorrhage: an alternative to hysterectomy? Five cases reported. Br J Obstet Gynaecol 1997;104(3):372-375. DOI: 10.1111/j.1471-0528.1997.tb11471.x.

21. Hayman RG, Arulkumaran S, Steer PJ. Uterine compression sutures: surgical management of postpartum hemorrhage. Obstet Gynecol 2002;99(3):502-506. DOI: 10.1016/s0029-7844(01)01643-x.

22. Matsubara S, Yano H, Ohkuchi A, et al. Uterine compression sutures for postpartum hemorrhage: an overview. Acta Obstet Gynecol Scand 2013;92(4):378-385. DOI: 10.1111/aogs.12077.

23. Palacios-Jaraquemada JM. Efficacy of surgical techniques to control obstetric hemorrhage: analysis of 539 cases. Acta Obstet Gynecol Scand 2011;90(9):1036-1042. DOI: 10.1111/j.1600-0412.2011.01176.x.

24. Fotopoulou C, Dudenhausen JW. Uterine compression sutures for preserving fertility in severe postpartum haemorrhage: an overview 13 years after the first description. J Obstet Gynaecol 2010;30(4): 339-349. DOI: 10.3109/01443611003650233.

25. Hackethal A, Brueggmann D, Oehmke F, et al. Uterine compression $\mathrm{U}$-sutures in primary postpartum hemorrhage after Cesarean section: fertility preservation with a simple and effective technique. Hum Reprod 2008;23(1):74-79. DOI: 10.1093/humrep/dem364.

26. Kayem G, Kurinczuk JJ, Alfirevic Z, et al. Uterine compression sutures for the management of severe postpartum hemorrhage. Obstet Gynecol 2011;117(1):14-20. DOI: 10.1097/AOG.0b013e318202c596.

27. Allahdin S, Aird C, Danielian P. B-Lynch sutures for major primary postpartum haemorrhage at caesarean section. J Obstet Gynaecol 2006:26(7):639-642. DOI: 10.1080/01443610600903586.
28. Amorim-Costa C, Mota R, Rebelo C, et al. Uterine compression sutures for postpartum hemorrhage: is routine postoperative cavity evaluation needed? Acta Obstet Gynecol Scand 2011;90(7):701-706. DOI: 10.1111/j.1600-0412.2011.01137.x.

29. Ouahba J, Piketty $M$, Huel $C$, et al. Uterine compression sutures for postpartum bleeding with uterine atony. BJOG 2007;114(5):619-622. DOI: 10.1111/j.1471-0528.2007.01272.x.

30. Mallappa Saroja CS, Nankani A, El-Hamamy E. Uterine compression sutures, an update: review of efficacy, safety and complications of B-Lynch suture and other uterine compression techniques for postpartum haemorrhage. Arch Gynecol Obstet 2010;281(4):581-588. DOI: 10.1007/s00404-009-1249-z.

31. B-Lynch C, Coker A, Lawal AH, et al. The B-Lynch surgical technique for the control of massive postpartum hemorrhage: an alternative to hysterectomy? Five cases reported. Br J Obstet Gynaecol 1997;104(3):372-375. DOI: 10.1111/j.1471-0528.1997.tb11471.x.

32. Holtsema H, Nijland R, Huisman A. The B-Lynch technique for postpartum hemorrhage: an option for every gynaecologist. Eur J Obstet Gynecol Reprod Biol 2004;115(1):39-42. DOI: 10.1016/ j.ejogrb.2003.09.049.

33. Api M, Api O, Yayla M. Fertility after B-Lynch suture and hypogastric artery ligation. Fertil Steril 2005;84(2):509. DOI: 10.1016/ j.fertnstert.2005.01.140.

34. Habek D, Vranjes M, Bobic Vukovic M, et al. Successful term pregnancy after B-Lynch compression suture in a previous pregnancy on account of massive primary postpartum hemorrhage. Fetal Diagn Ther 2006;21(5):475-476. DOI: 10.1159/000093892.

35. Baskett TF. Uterine compression sutures for postpartum hemorrhage: efficacy, morbidity, and subsequent pregnancy. Obstet Gynecol 2007;110(1):68-71. DOI: 10.1097/01. AOG.0000267499.40531.a4.

36. Vitthala S, Misra PK. Fertility after B-Lynch suture in a patient previously treated for acute myeloid leukaemia. Eur J Obstet Gynecol Reprod Biol 2008;136(1):133-134. DOI: 10.1016/j.ejogrb.2006.09.016.

37. Roy KK, Baruah J, Sharma JB, et al. Reproductive outcome following hysteroscopic adhesiolysis in patients with infertility due to Asherman's syndrome. Arch Gynecol Obstet 2010;281(2):355-361. DOI: 10.1007/s00404-009-1117-x.

38. Schenker JG, Margalioth EJ. Intrauterine adhesions: an updated appraisal. Fertil Steril 1982;37(5):593-610. DOI: 10.1016/ s0015-0282(16)46268-0. 